\title{
Structure and Evolution of Non-Lake-Effect Snow Producing Alberta Clippers
}

\author{
Jake Wiley *(1) and Andrew Mercer $(\mathbb{C}$ \\ Department of Geosciences, Mississippi State University, 75 B. S. Hood Road, Starkville, MS 39762, USA; \\ mercer@gri.msstate.edu \\ * Correspondence: jew439@msstate.edu
}

check for

updates

Citation: Wiley, J.; Mercer, A. Structure and Evolution of NonLake-Effect Snow Producing Alberta Clippers. Atmosphere 2021, 12, 1288. https://doi.org/10.3390/atmos12101288

Academic Editor: John Walsh

Received: 15 September 2021

Accepted: 1 October 2021

Published: 2 October 2021

Publisher's Note: MDPI stays neutral with regard to jurisdictional claims in published maps and institutional affiliations.

Copyright: (c) 2021 by the authors. Licensee MDPI, Basel, Switzerland. This article is an open access article distributed under the terms and conditions of the Creative Commons Attribution (CC BY) license (https:// creativecommons.org/licenses/by/ $4.0 /)$.

\begin{abstract}
Alberta Clippers (clippers) have long been associated with lake-effect snow (LES) events due to their frequent passage over the Great Lakes basin. However, not all clippers produce LES, and no research has inquired into which synoptic fields most influence LES formation. This study analyzes clippers during non-LES situations to further knowledge on which atmospheric variables most regulate LES development on the synoptic scale. As no such database currently exists, a clipper repository is developed using National Centers for Environmental Prediction Reanalysis data. The repository is then cross referenced with a previously developed LES repository to identify clippers responsible for LES. Composite synoptic-scale patterns were then constructed on the remaining non-LES clippers to identify synoptic conditions that ultimately inhibited LES formation. This analysis is supplemented by an assessment of lake surface conditions in each composite to evaluate how influential the lake characteristics were in the suppression of LES activity. In total, 51 non-LES clippers were identified, tracked, and separated into three composite map types that exhibited unique storm track and spatial characteristics. Permutation testing revealed that lake surface conditions were not significantly $(p \leq 0.05)$ different between LES and non-LES associated clippers implying the main LES inhibition factors were meteorological.
\end{abstract}

Keywords: lake-effect snow; mid-latitude cyclones; synoptic; Great Lakes; Alberta Clipper; winter weather; climatology

\section{Introduction}

Mid-latitude cyclones (hereafter referred to as 'cyclones') have been studied frequently, as knowledge of the dynamics, structure, and tracks comprising these storms is critical for mitigation of their impacts. Cyclones form in areas of enhanced thermal contrasts as baroclinic instability leads to the transformation of potential to kinetic energy [1] (p. 98). These cyclones have a dominant role in influencing atmospheric processes on various spatial and temporal scales. For example, prior research has linked cyclones with severe tornado outbreaks [2,3], global poleward heat transport [4,5], regional seasonal precipitation distribution [6], and blizzard conditions [7]. Though cyclones can form in any region of enhanced baroclinicity, the complex topography of North America (elevated landmasses adjacent to major ocean currents, etc.) render distinct regions favorable for cyclogenesis [8], resulting in frequent cyclone development and propagation over the continental U.S. This is most pronounced during the North American cool season when the polar jet stream is strongest. Previous studies have identified three major cyclogenesis regions and associated storm tracks that have unique characteristics and impacts: the Colorado cyclone, East Coast cyclone, and Alberta Clipper [8-14].

One of the less studied aspects of cyclones is their indirect contribution to the formation of lake-effect snow (LES) off the North American Great Lakes (hereafter referred to as 'Great Lakes'). While LES occurs across the globe (e.g., Great Salt Lake (North America), Great Slave Lake (North America), Lake Baikal (Asia), Baltic Sea (Europe)) [15] (p. 17), 
the Great Lakes are where LES occurs most frequently and severely due to several physiographic characteristics (size, orientation, etc.). One unique characteristic is the Great Lakes' geographic location, as they are situated along one of the major North American storm tracks (Alberta Clipper-Figure 1) meaning they are regularly impacted by cyclones. However, LES is not typically generated by frontal forcing mechanisms, unlike most cyclone-induced precipitation. Rather, the advection of continental polar air (associated with the cyclone's cold front) over a relatively warmer lake surface results in air mass modification, destabilization of the planetary boundary layer (PBL), and enhanced energy fluxes [16-21]. This lake-induced instability, combined with supplementary environmental factors (open fetch, steep low-level frictional convergence, minimal lake ice coverage, etc.), warm and moisten the PBL above the lake surface which results convective updraft formation and the eventual development of elongated snow bands over the lake surface that stretch inland into the lake's lee [18,20-25]. While the mesoscale conditions linked with LES have been extensively investigated [26-34], studies characterizing the synoptic environments associated with LES remain limited, though contemporary studies are beginning to integrate updated analysis techniques to identify synoptic-scale structures underlying LES $[35,36]$. In our study, we will focus specifically on the role of the cyclone track (the Alberta Clipper (hereafter clipper)) that is most responsible for LES, and which synoptic conditions and processes associated with clippers are most influential to LES formation.

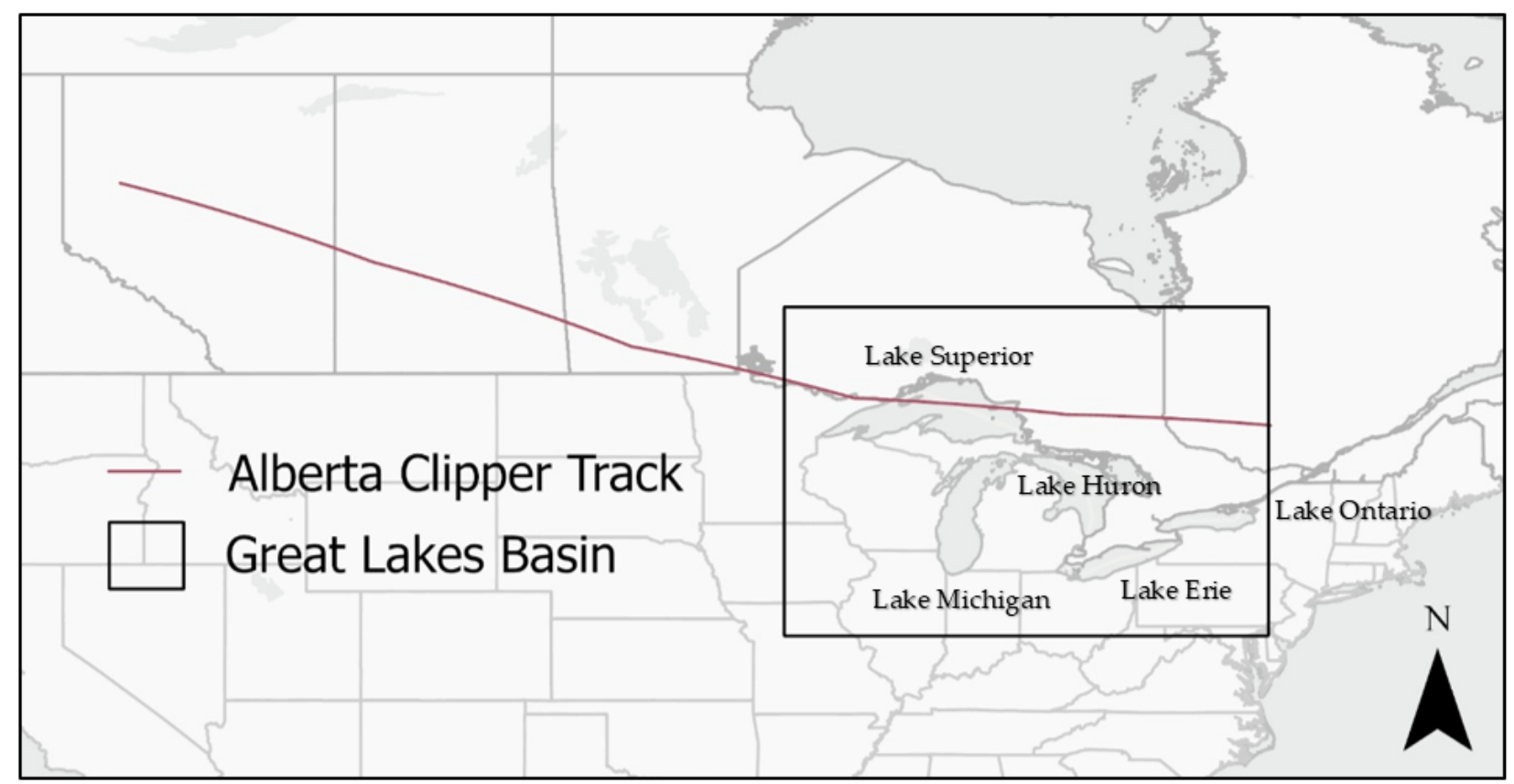

Figure 1. Climatological track of Alberta Clippers based on [2]. The red line denotes the track while the outlined rectangle encapsulates the Great Lakes Basin.

Typically, clippers first evolve as an antecedent west coast cyclone makes landfall west/northwest of the Canadian Rocky Mountains [37]. While the cyclone propagates east towards Alberta, Canada, cross mountain flow increases, resulting in leeward adiabatic warming and the development of a lee trough [38,39]. As the cyclone continues propagating and traverses the Rockies, synoptic vertical ascent associated with quasigeostrophic (QG) omega forcing becomes prevalent atop of the low-level lee trough, resulting in contrasting vertical circulations characterized by low-level descent and mid- and upper-level ascent. Vortex stretching ensues which, when combined with enhanced baroclinicity via the cross mountain zonal thermal contrast as well as differential positive vorticity advection (PVA), culminates in the development of a clipper on the lee side of the Canadian Rockies. Once developed, clippers track east/southeast (Figure 1) where thermal advection and upperlevel forcing patterns are strongest [40]. 
Clippers are generally considered weak cyclones that feature high propagation speeds and rarely produce substantial precipitation $[14,41]$ owing to a deficiency of moisture availability and lower thermodynamic energy availability. Clippers are also not typically associated with severe convective weather due to their relatively weak thermal gradients and QG forcing compared to other storm tracks [14]. However, clippers have been linked with strong wind events with gusts up to $38 \mathrm{~m} \mathrm{~s}^{-1}$ which can cause power outages, infrastructure damage, wildfires, and blizzard conditions [42,43]. Fall winds (also known as frontal chinooks) are frequently observed leeward of the Rockies as continental polar air associated with the clipper's cold front is advected across the mountain range, resulting in higher density air to flow and accelerate across the eastern slopes. Additionally, as the clipper propagates and matures, an anticyclone will typically build in its wake which creates a pressure dipole and tight isobaric gradient between the two pressure systems. As $[35,36]$ note, in addition to strong flow, this dipole has also been linked with LES off the Great Lakes.

Previous studies have outlined the following conditions as typical for a synoptic environment comprising Great Lakes LES [35,36,44-46]:

- $\quad$ mid-tropospheric low-pressure anomaly situated near the Hudson Bay;

- cyclone east/northeast of the Great Lakes (typically a clipper);

- anticyclone west/southwest of the Great Lakes.

This surface dipole structure (Figure 2) results in synoptic scale cold air advection (CAA) (linked with the cyclone and associated cold front) and LES conducive PBL wind regimes characterized by west/northwesterly flow. This pattern promotes air parcel trajectories over maximum amounts of open lake fetch. Synoptic scale forcing plays a secondary role in LES formation by modifying the low-level wind field which plays an instrumental role in LES morphology. That is, the low-level flow regime, which is dictated by the overlying synoptic environment, directly governs which types of snow bands (long-lake axis parallel, widespread coverage, etc. [20]) form during LES events. This was observed in [35] and [36] who found that, for a PBL thermodynamic profile conducive to LES formation, subtle variations in the surface dipole structure driven by deviations in the synoptic scale pattern led to varying LES snow band types and impacts.
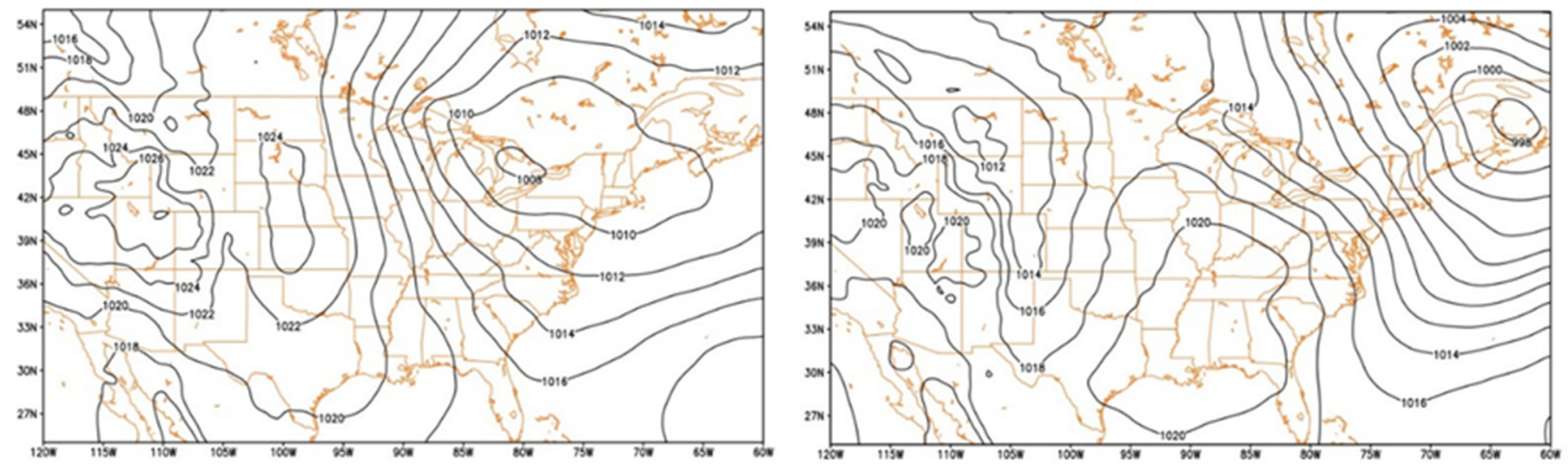

Figure 2. From [35] highlighting the evolution of the common dipole structure present during a LES event off the eastern Great Lakes (Lakes Erie and Ontario).

Of course, not all clippers result in this dipole structure, and even if the dipole is formed, LES still may not develop. The exact reasons for this are not known, despite advances in understanding the synoptic-scale's role in driving LES. Understanding the unique synoptic-scale dynamics of non-LES associated cyclones will supplement our current knowledge of LES-conducive synoptic-scale patterns and assist local forecasters with predicting LES with greater lead time. As such, the purpose of our study is to examine the synoptic scale characteristics of wintertime clippers that do not result in eventual Great 
Lakes LES production and differentiate those patterns from traditional LES synoptic-scale configurations. The resulting patterns will be compared with their underlying mesoscale and lake-surface conditions to ensure differences between LES and non-LES environments are primarily meteorological.

Section 2 describes methods employed for developing a clipper repository, reanalysis datasets used, and statistical analysis techniques for creating the synoptic composites. Section 3 presents a preliminary analysis of the clipper repository and a comprehensive examination of the synoptic composites and provides a discussion on the influence of the synoptic environment on LES suppression by analyzing the mesoscale environment. Finally, Section 4 summarizes the results and discusses future work.

\section{Materials and Methods}

\subsection{Alberta Clipper Repository}

The research objectives require a robust database of historic clippers. The work in [37] developed such a repository using European Centre for Medium-Range Weather Forecasts (ECMWF) Tropical Ocean Global Atmosphere (TOGA) data during 15 boreal cold seasons (October-March) spanning 1986/87 to 2000/01. They classified a cyclone as a clipper based on five propagation and intensity criteria based on mean sea level pressure (MSLP) and vorticity fields (see [37] for a full description). Our study utilized a similar approach, adapting these criteria to National Centers for Environmental Prediction (NCEP) National Center for Atmospheric Research (NCAR) Reanalysis data [47] that spans 11 meteorological winters (December-February) including 1997/98, 1998/99, and 2005/06 to $2013 / 2014$. These specific time periods were selected to align with LES repositories in [35] and [36] which were used to categorize clippers as associated/disassociated with LES. Meteorological winter (December-February) was selected as the temporal domain for this study owing to the climatological frequency of clippers [37], and only 48 (16.5\%) LES cases occurred outside the winter months. The NCEP/NCAR reanalysis dataset was selected to develop the clipper repository as it features an equal spatial $\left(2.5^{\circ}\right)$ and higher temporal ( $6 \mathrm{~h}$ ) resolution to that of the ECMWF TOGA data used by [37] and has been used in previous work [14] characterizing clipper environments. All cyclone identification and tracking was performed on a spatial domain spanning $25^{\circ} \mathrm{N}-75^{\circ} \mathrm{N}$ and $150^{\circ} \mathrm{W}-30^{\circ} \mathrm{W}$, a domain seen in previous studies $[8,14,37]$ when characterizing clipper climatology. For a cyclone/local MSLP minimum of interest to be classified a clipper, the following conditions must be met (note these were based heavily on the work in [37]):

1. Cyclogenesis in the lee of the Canadian Rocky Mountains within the Canadian provinces of Yukon, Northwest Territories, British Columbia, and/or Alberta as evidenced by a closed circulation and/or evident local MSLP minimum (based on $2 \mathrm{mb}$ intervals);

2. Closed circulation and/or evident local MSLP minimum present for $60 \mathrm{~h}$ once the system makes major progress east of the Canadian Rocky Mountains (hereafter referred to as 'time of departure');

3. System propagates southeast towards U.S-Canadian border immediately after time of departure whereafter it tracks east and/or southeast;

4. System is located east of $90^{\circ} \mathrm{W}$ within $60 \mathrm{~h}$ after time of departure (a measure of cyclone propagation speed).

Based on these criteria, 78 total clippers were identified over the 11 meteorological winters previously mentioned (Table 1 ). 
Table 1. Monthly breakdown of recorded clippers over the 11 meteorological winters used for this study. Bold face numbers represent monthly or yearly totals and the numbers in parentheses show the percentage of clippers relative to the total number of clippers identified in the repository.

\begin{tabular}{ccccc}
\hline Year & December & January & February & Yearly Total \\
\hline $1997 / 98$ & 2 & 2 & 0 & $\mathbf{4}$ \\
$1998 / 99$ & 3 & 1 & 3 & $\mathbf{1 1}$ \\
$2005 / 06$ & 3 & 5 & 3 & $\mathbf{9}$ \\
$2006 / 07$ & 3 & 4 & 2 & $\mathbf{6}$ \\
$2007 / 08$ & 3 & 1 & 2 & $\mathbf{2}$ \\
$2008 / 09$ & 3 & 4 & 0 & $\mathbf{2}$ \\
$2009 / 10$ & 1 & 1 & 0 & $\mathbf{8}$ \\
$2010 / 11$ & 2 & 2 & 1 & $\mathbf{1 0}$ \\
$2011 / 12$ & 3 & 4 & 1 & $\mathbf{9}$ \\
$2012 / 13$ & 3 & 5 & 2 & $\mathbf{7 8}$ \\
$2013 / 14$ & 2 & 5 & 2 & $\mathbf{1 6}(\mathbf{2 0 . 5 \% )}$ \\
Monthly Total & $\mathbf{2 8}(\mathbf{3 5 . 9 \% )}$ & $\mathbf{3 4}(\mathbf{4 3 . 6 \% )}$ & &
\end{tabular}

On average, 7.1 clippers occurred every winter, consistent with [37] who found that approximately 7.2 clippers occur per winter. Interestingly, the intraseasonal distribution differed slightly with [37], as most clippers identified in our study occurred in January, while their work found most clippers occurred in December. These differences were attributed to the small temporal span in both studies. Once identified, clippers were visually tracked using the Grid Analysis and Display System [48] and ArcGIS Pro version 2.5.0 [49]. These mapping and visualization tools were used in tandem to locate and record the position of the lowest MSLP from the NCEP/NCAR data, noted as the clipper's center, an approach consistent with numerous prior cyclone-tracking studies with similar objectives [37,50-52]. Finally, the 'end time' for each clipper was identified as the NCEP/NCAR timestep where the MSLP minima was no longer present in the domain as it crossed $50^{\circ} \mathrm{W}$ or $60^{\circ} \mathrm{N}$. This methodology resulted in a clipper repository that contained the following cyclone characteristics:

- Time of departure date and location;

- End time date and location;

- Complete track of system throughout its duration as marked by NCEP/NCAR Reanalysis grid points at six-hour timesteps.

Once finalized, each clipper system in the repository was categorized a LES or nonLES producing clipper by cross-referencing the clipper repository with the LES repository from $[35,36]$. For a clipper to be linked to LES formation, it must have influenced the surface flow regime over the associated lake during the LES event start time. This influence was determined visually by examining all LES events that started within the life span of a given clipper and comparing the MSLP setup with the surface wind field over the lake. If that wind field was predominantly a result of the clipper system under investigation, the clipper was logged as being 'LES associated'. This approach yielded $21(26.9 \%)$ of the 78 total clippers being LES associated, with the remaining 57 cases non-LES associated.

\subsection{Data and Statistical Methods}

Once established, the non-LES clipper database ( $\mathrm{N}=57$ cases) was used to construct a synoptic climatology using a T-mode principal component analysis (PCA) combined with a k-means cluster analysis (CA) to obtain climatological map types. These methods have been shown to be useful in numerous studies $[3,35,36,44]$ as they identify temporal modes of variability among atmospheric data and use that information to group individual members (i.e., clippers for this study) into distinct clusters from which composites can be constructed. 
Though the NCEP/NCAR reanalysis was optimal for developing the clipper repository (owing to its reliance on the synoptic scale), its spatial and temporal resolution were not ideal for representing the mesoscale conditions associated with the clippers. Instead, the North American Regional Reanalysis (NARR) dataset [53] was used to construct the synoptic climatology of the non-LES clippers as it features a higher spatial $(32 \mathrm{~km})$ and temporal $(3 \mathrm{~h})$ resolution than the NCEP/NCAR reanalysis while encompassing the study period and spatial domain. In total, 41 meteorological variables were retained from the NARR to characterize the synoptic and mesoscale conditions within each clipper, including five surface fields (mean sea-level pressure (MSLP), 10-m zonal and meridional wind components, skin temperature, and specific humidity) and five three-dimensional fields (zonal and meridional ( $\mathrm{u}$ and $\mathrm{v}$ ) wind components, geopotential height, temperature $(\mathrm{T})$, and specific humidity (q)) captured at seven isobaric levels $(1000 \mathrm{mb}, 925 \mathrm{mb}, 850 \mathrm{mb}, 700 \mathrm{mb}$, $500 \mathrm{mb}, 300 \mathrm{mb}$, and $250 \mathrm{mb}$ ). All fields were retained for $96 \mathrm{~h}$, beginning with the respective clipper's time of departure over a spatial domain that extended from $25^{\circ} \mathrm{N}-65^{\circ} \mathrm{N}$ and $130^{\circ} \mathrm{W}-40^{\circ} \mathrm{W}$ and included 30,352 NARR gridpoints (a near match to the domain used for the clipper repository).

Importantly, in this study, it was unknown which timestep(s) of the NARR would best characterize the distinctions between LES and non-LES environments, as each clipper had different evolutionary characteristics (cyclogenesis location, propagation speed, etc.). As no LES occurred in the non-LES clippers, we estimated the geographic position of the clippers where LES would most likely occur as the locations where these distinctions should be found. This was achieved by computing the mode longitude of the 21 LES associated clippers (as discussed above) at the time LES began. This longitude $\left(75^{\circ} \mathrm{W}\right)$ marked the location where clipper associated LES was most likely to form, though this longitudinal distribution was clearly bimodal (Figure 3), an important limitation of this approach. We addressed this issue by selecting NARR fields from two longitudinal positions in the clipper's lifespan $\left(75^{\circ} \mathrm{W}\right.$ and $\left.90^{\circ} \mathrm{W}\right)$ to serve as an objective spatial and temporal framework from which non-LES associated clippers could be compared with their LES counterparts. Note that six non-LES and two LES clippers (roughly $10 \%$ ) did not track east of $75^{\circ} \mathrm{W}$ and fell outside of the bimodal distribution. These systems were excluded from further analysis, as they did not characterize the overlying patterns of the other clippers (resulting in 51 and 19 total non-LES and LES clippers, respectively).

Once the non-LES fields were retained, synoptic-scale composites of the dominant patterns in these environments were constructed following [35,36]. The composite methodology required several tuning/optimization steps before final map types could be constructed. These steps included determining which NARR fields best distinguish the clipper environments, the number of principal components (PCs) to retain from the PCA, and number of clusters/map types from the CA. These steps were completed by conducting numerous PCAs and CAs on 11 combinations of NARR fields representing the 51 nonLES cases (Table 2) and quantifying variance explained by the resulting PCs, as well as silhouette coefficients [54] associated with each CA. 


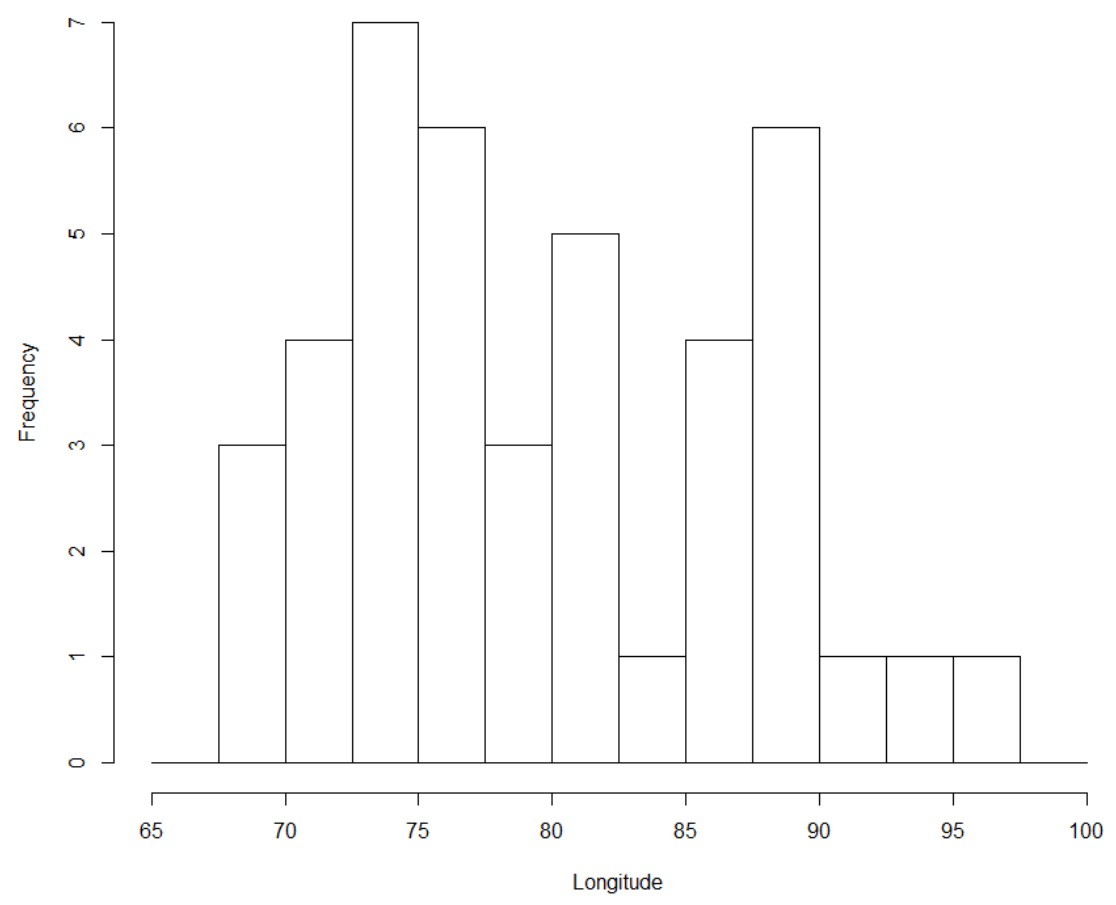

Figure 3. Histogram of longitude locations of LES-associated clippers during the start of LES formation. These values are associated with 41 LES events from the Mercer and Wiley (2020) and Wiley and Mercer (2021) LES repository. Note the bimodal distribution featuring a high frequency of longitudes around $75^{\circ} \mathrm{W}$ (mode longitude) and $90^{\circ} \mathrm{W}$. These two locations mark the positions of clippers that resulted in LES across the eastern (Lakes Erie and Ontario) and western (Lakes Michigan and Superior) Great Lakes, respectively.

Table 2. Various NARR configurations tested to evaluate the optimal fields to retain for the PCA and CA. Starred fields represent the configuration used for the statistical analysis.

\begin{tabular}{|c|c|}
\hline Experiment Number & NARR Variables Used to Construct PCA \\
\hline 1 * & MSLP * \\
\hline 2 & MSLP, $10-\mathrm{m}$ winds \\
\hline 3 & MSLP, 10-m winds, $1000 \mathrm{mb} \mathrm{T}$ \\
\hline 4 & MSLP, $10-\mathrm{m}$ winds, $1000 \mathrm{mb}$ T, $2-\mathrm{m} \mathrm{q}$ \\
\hline 5 & MSLP, $10-\mathrm{m}$ winds, $1000 \mathrm{mb}$ T, 2-m q, $850 \mathrm{mb}$ heights, $850 \mathrm{mb}$ winds \\
\hline 6 & $\begin{array}{l}\text { MSLP, 10-m winds, } 1000 \mathrm{mb} \mathrm{T}, 2-\mathrm{m} \mathrm{q}, 850 \mathrm{mb} \text { heights, } 850 \mathrm{mb} \text { winds, } \\
850 \mathrm{mb} \text { T, } 850 \mathrm{mb} \mathrm{q}\end{array}$ \\
\hline 7 & MSLP, 10-m winds, $1000 \mathrm{mb} \mathrm{T}, 2-\mathrm{m} \mathrm{q}, 500 \mathrm{mb}$ heights, $500 \mathrm{mb}$ winds \\
\hline 8 & $\begin{array}{l}\text { MSLP, 10-m winds, } 1000 \mathrm{mb} \mathrm{T}, 2-\mathrm{m} \mathrm{q}, 500 \mathrm{mb} \text { heights, } 500 \mathrm{mb} \text { winds, } \\
500 \mathrm{mb} \mathrm{T}, 500 \mathrm{mb} \mathrm{q}\end{array}$ \\
\hline 9 & $\begin{array}{l}\text { MSLP, } 10 \text {-m winds, } 1000 \mathrm{mb} \text { T, } 2-\mathrm{m} \mathrm{q}, 850 \mathrm{mb} \text { heights, } 850 \mathrm{mb} \text { winds, } \\
500 \mathrm{mb} \text { heights, } 500 \mathrm{mb} \text { winds }\end{array}$ \\
\hline 10 & $\begin{array}{l}\text { MSLP, 10-m winds, } 1000 \mathrm{mb} \text { T, 2-m q, } 850 \mathrm{mb} \text { heights, } 850 \mathrm{mb} \text { winds, } \\
850 \mathrm{mb} \text { T, } 850 \mathrm{mb} \mathrm{q}, 500 \mathrm{mb} \text { heights, } 500 \mathrm{mb} \text { winds, } 500 \mathrm{mb} \mathrm{T}, 500 \mathrm{mb} \mathrm{q}\end{array}$ \\
\hline 11 & All NARR variables originally retained \\
\hline
\end{tabular}

We employed methods from [36] to determine the optimal PCA/CA configuration and tested all permutations of retaining 2-10 PCs and 2-10 clusters for each NARR configuration (i.e., 'Experiment'; Table 2). The PC-cluster combination selected to construct the composites was based on the amount of variance explained by the PCs, the average silhouette coefficient, and the frequency of misclustered cases (negative silhouettes). Among the 11 experiments, 'Experiment 1', which consisted of only retaining MSLP, two PCs, and three clusters, was deemed best, as its PCs explained the most variance (25.9\%) and featured the second highest silhouette coefficient (0.442) with only one misclustered clipper (Table 3). 
Figure 4 shows the distinctiveness of the PC loadings, revealing that Cluster 1 is generally associated with PC1 loading values that are positive, while Cluster 2 had positive PC2 and negative PC1 values and Cluster 3 had negative PC1 and PC2 values. Interestingly, the addition of more NARR variables appeared to deteriorate analysis performance as metrics used to evaluate the PCA and CA generally decreased through the progression of the experiments. This suggests that MSLP was the most distinguishing atmospheric field among the NARR fields tested, which parallels the findings of $[35,36]$ who found that MSLP was the least correlated atmospheric field among synoptic composites of LES events. It should be noted that MSLP was the only NARR field to be tested individually, owing to its characterization of the dipole structure thought to be of critical importance for LES formation in previous work $[35,36,44-46]$.

Table 3. Statistical results from experiments used to identify the optimal PCA and CA configuration. Each of the listed values from each experiment represent the most optimal PC-cluster configuration associated with the NARR field(s) retained for that specific experiment. Starred fields represent the configuration used for the statistical analysis.

\begin{tabular}{cccccc}
\hline $\begin{array}{c}\text { Experiment } \\
\text { Number }\end{array}$ & $\begin{array}{c}\text { PCs } \\
\text { Retained }\end{array}$ & $\begin{array}{c}\text { Clusters } \\
\text { Used }\end{array}$ & $\begin{array}{c}\text { Variance } \\
\text { Explained }\end{array}$ & $\begin{array}{c}\text { Silhouette } \\
\text { Coefficient }\end{array}$ & $\begin{array}{c}\text { Number of } \\
\text { Misclusters }\end{array}$ \\
\hline $1^{*}$ & $2 *$ & $3 *$ & $25.9 \% *$ & $0.442 *$ & $1 *$ \\
2 & 2 & 4 & $18.8 \%$ & 0.434 & 0 \\
3 & 2 & 3 & $19.6 \%$ & 0.426 & 0 \\
4 & 2 & 10 & $19.4 \%$ & 0.480 & 0 \\
5 & 2 & 9 & $18.7 \%$ & 0.448 & 0 \\
6 & 2 & 10 & $18.7 \%$ & 0.397 & 0 \\
7 & 2 & 10 & $19.1 \%$ & 0.387 & 0 \\
8 & 2 & 7 & $18.5 \%$ & 0.431 & 0 \\
9 & 2 & 8 & $18.5 \%$ & 0.400 & 0 \\
10 & 2 & 5 & $18.3 \%$ & 0.428 & 1 \\
11 & 2 & 5 & $17.9 \%$ & 0.425 & 0 \\
\hline
\end{tabular}

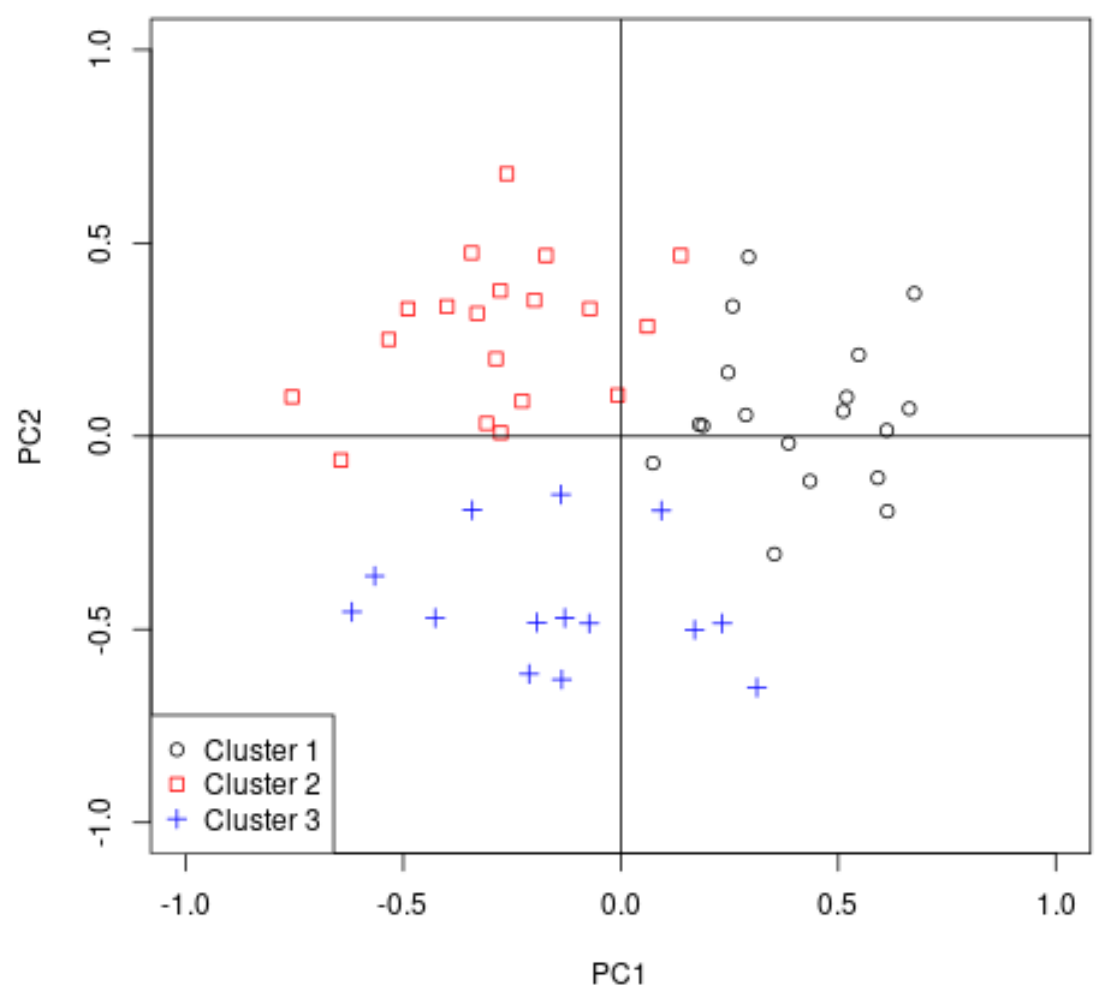

Figure 4. Scatterplot of the first two PC loadings for the 51 non-LES clippers. The $x$ axis denotes loading vectors from the first PC and the $y$ axis denotes loading vectors from the second PC. 
With the optimal PCA-CA configuration identified, a nonhierarchical k-means CA was used to separate the 51 non-LES clippers into three distinct clusters (Figure 4) based on variability structures identified by the PCA. Clippers in each cluster were averaged to construct to three sets of synoptic composites that depicted atmospheric conditions for all clippers in each group (map types) at each reference longitude $\left(75^{\circ} \mathrm{W}\right.$ and $\left.90^{\circ} \mathrm{W}\right)$. Finally, a set of mean composites for the 19 LES clippers were constructed as a reference to compare against the non-LES patterns derived from the composite analysis described above.

\subsection{Diagnostic Variables}

Following [35,36], MSLP and upper-level geopotential height fields were used to diagnose synoptic-scale structure and forcing patterns. Additionally, a derived quasigeostrophic $(Q G)$ variable was calculated to assess synoptic-scale vertical motion. When assessing synoptic-scale vertical motion, using the traditional QG omega diagnostic approach can prove difficult in situations when differential geostrophic vorticity advection and temperature advection counter one another, yielding indeterminate vertical motion insight even though such motion may be present. This issue was present in our analysis (not shown), so we elected to utilize a derived QG diagnostic that blends both terms in the QG omega equation by coupling geostrophic horizontal shear with the horizontal temperature gradient on an isobaric surface, a quantity known as the $Q$-vector [55]. $Q$ is directly related to QG omega through:

$$
\left(\nabla_{p}^{2}+\frac{f_{0}^{2}}{\sigma} \frac{\partial^{2}}{\partial p^{2}}\right) \omega=-2 \nabla_{p} \cdot \mathrm{Q},
$$

where $Q$ is defined as:

$$
\mathrm{Q}=\left(\begin{array}{l}
\mathrm{Q}_{1} \\
\mathrm{Q}_{2}
\end{array}\right)=-\frac{R}{p \sigma}\left(\begin{array}{c}
\frac{\partial \mathrm{v}_{g}}{\partial x} \cdot \nabla_{p} T \\
\frac{\partial \mathrm{v}_{g}}{\partial y} \cdot \nabla_{p} T
\end{array}\right),
$$

This relationship shows that areas with Q-vector convergence (divergence) are colocated with synoptic-scale ascent (descent). Following the methods of [14], static stability $(\sigma)$ was excluded from the $Q$ calculations as it can be divided out as a scalar without altering the direction of $\mathrm{Q}$ (as $\sigma$ is almost always positive for large-scale synoptic analysis).

In addition to the synoptic-scale analysis, a mesoscale analysis was completed which characterized the role of surface-atmosphere stability and lapse rates in LES suppression. Low-level (1000-850 mb) lapse rates were calculated over a NARR grid point (Figure 5) centered over each lake (resulting in five lapse rates for five lakes) to evaluate stability. These lake-centric grid points were selected as they feature the highest lake surface temperatures due to the lakes' bathymetry patterns and are co-located the location of where LES associated convection would be most likely to develop initially. Finally, surface specific humidity (q) fields were evaluated to assess atmospheric moisture content.

To ensure the LES suppression mechanisms were meteorological, lake surface conditions were also analyzed separately given their importance on LES development. Specifically, if stark differences in the lake surface temperatures and lake ice cover arose between LES and non-LES clippers, this would suggest lake conditions were the primary factors differentiating LES and non-LES cases. Lake temperature data were retained from the daily Great Lakes Surface Environmental Analysis (GLSEA) Surface Water Temperature Data archive [56], while lake ice cover was based on the GLSEA Great Lakes Average Ice Cover Data [56] which features daily lake average ice cover. It should be noted that the ice cover dataset began December 2008 which resulted in a portion of the clippers $(42.9 \%)$ being excluded from the ice cover analysis. 


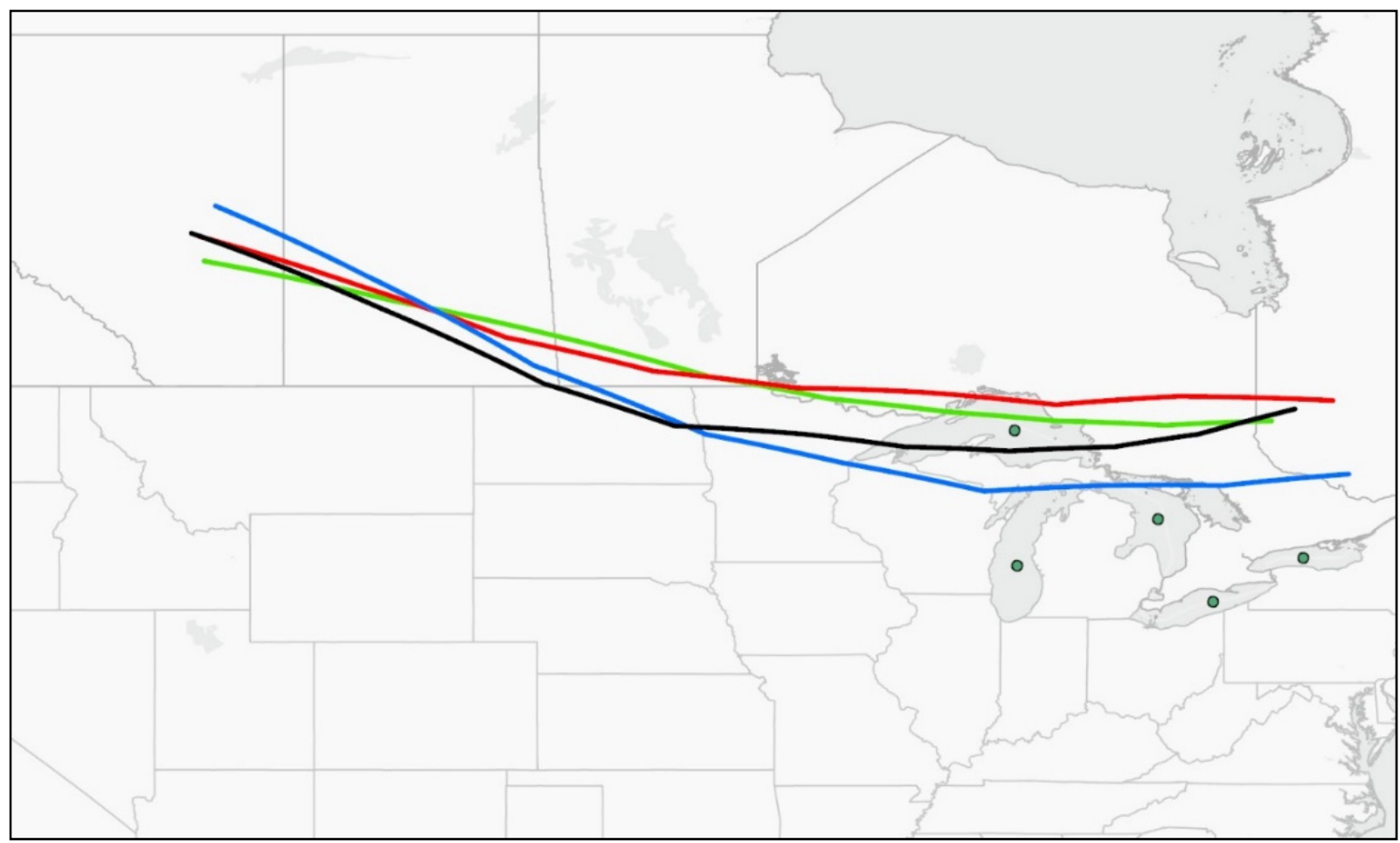

Figure 5. Composite tracks of Cluster 1 (green line), Cluster 2 (red line), Cluster 3 (blue line), and LES associated (black line) clippers from $t=0 \mathrm{~h}$ (time of departure) to $t=54 \mathrm{~h}$. Outlined dark green dots represent the NARR grid points used to calculate low-level lapse rates.

\section{Results and Discussion}

\subsection{Influence of Lake Surface Characteristics on LES Suppression}

To quantify the role of lake surface conditions on LES suppression, Table 4 presents average lake surface temperatures and ice covers of all LES and non-LES clippers across all Great Lakes. Permutation tests of the mean [57] (p. 182) were used to establish statistical significance to the differences in LES and non-LES lake temperature and ice covers at each reference longitude.

Table 4. Mean lake surface conditions during non-LES clippers for both reference longitudes and LES clippers at the start of LES formation. No differences in the means were significant.

\begin{tabular}{cccccc}
\hline & $\begin{array}{c}\text { Lake } \\
\text { Superior }\end{array}$ & $\begin{array}{c}\text { Lake } \\
\text { Michigan }\end{array}$ & $\begin{array}{c}\text { Lake } \\
\text { Huron }\end{array}$ & $\begin{array}{c}\text { Lake } \\
\text { Erie }\end{array}$ & $\begin{array}{c}\text { Lake } \\
\text { Ontario }\end{array}$ \\
\hline Lake Surface Temperature & $2.63{ }^{\circ} \mathrm{C}$ & $3.49{ }^{\circ} \mathrm{C}$ & $2.76{ }^{\circ} \mathrm{C}$ & $2.46{ }^{\circ} \mathrm{C}$ & $3.77{ }^{\circ} \mathrm{C}$ \\
$\begin{array}{c}\text { (non-LES) } \\
\text { Lake Surface Temperature (LES) }\end{array}$ & $2.82{ }^{\circ} \mathrm{C}$ & $3.54{ }^{\circ} \mathrm{C}$ & $3.08{ }^{\circ} \mathrm{C}$ & $2.87{ }^{\circ} \mathrm{C}$ & $4.10{ }^{\circ} \mathrm{C}$ \\
Ice cover (non-LES) & $16.96 \%$ & $14.52 \%$ & $24.60 \%$ & $34.33 \%$ & $8.22 \%$ \\
Ice cover (LES) & $13.52 \%$ & $12.06 \%$ & $20.30 \%$ & $28.58 \%$ & $6.95 \%$ \\
\hline
\end{tabular}

Though warmer surface temperatures (roughly $0.25^{\circ} \mathrm{C}$ ) and lower ice covers (roughly $3.5 \%$ ) were observed with LES clippers, which are indictive of a more LES conducive environment, these differences were not statistically significant for any lake (Table 4). Across all lakes and reference longitudes, ice cover differed more than lake surface temperatures, as evidenced by smaller $p$-values (not shown). The lack of statistical contrast implies that the primary forcing mechanisms suppressing convective activity associated with non-LES clippers were not primarily based on lake conditions, but instead on the mesoscale and synoptic-scale environment. 


\subsection{Synoptic Analysis}

Clippers were mostly evenly distributed among the three resulting clusters $(\mathrm{N} 1=18$, $\mathrm{N} 2=19$, and N3 = 14). While storm characteristics varied among all clippers analyzed, each composite featured distinct underlying structures (Table 5) in terms of average storm speed, duration, and intensity.

Table 5. Breakdown of average storm characteristics of all clippers by cluster. The storm intensity refers to the MSLP value associated with NARR grid identified as the clipper's center.

\begin{tabular}{ccccc}
\hline & Cluster $\mathbf{1}$ & Cluster 2 & Cluster 3 & LES Composite \\
\hline Duration $(\mathrm{hrs})$ & 89.3 & 77.4 & 80.1 & 90.32 \\
Storm Intensity $(\mathrm{mb})$ & 999.7 & 1006.2 & 1021.7 & 999.9 \\
Propagation Speed $\left(\mathrm{m} \mathrm{s}^{-1}\right)$ & 15.85 & 16.83 & 18.46 & 15.93 \\
\hline
\end{tabular}

Cluster 1's composites were characterized by typical clipper propagation characteristics [37] highlighted by a closed low-pressure circulation in the Canadian Rockies lee $\left(53^{\circ} \mathrm{N}, 112.5^{\circ} \mathrm{W}\right)$ that tracked southeast through the first $24 \mathrm{~h}$ before taking on a more westerly track clipping the U.S.-Canadian border (Figure 5). Cluster 1 featured the strongest non-LES systems characterized by the lowest central pressure values, slowest propagation speeds, longest average duration, and were most comparable to LES systems of all clusters (Table 5). However, Cluster 1 systems generally tracked further north than LES clippers without as much meridional variation altering the surface flow regime (not shown). Composite NARR fields exemplified these characteristics with a $500 \mathrm{mb}$ trough present at both reference longitudes collocated with a surface low-pressure system (Figures 6a and 7a). The initial westward displacement of the upper-level feature from the surface cyclone at $97.5^{\circ} \mathrm{W}$ (not shown) suggests the system was in the 'open wave' stage of development based on the Norwegian Cyclone Model [58].

Upper-level forcing in Cluster 1's composite (Figure 6a) was weaker relative to LES systems (Figure 6d) as only a small area of $Q$ convergence was observed over the southcentral coast of Lake Superior at $90^{\circ} \mathrm{W}$ (Figure 6a). This was likely due to weak $\left(0-5 \mathrm{~m} \mathrm{~s}^{-1}\right)$ southerly flow resulting in weak warm air advection (WAA) that enhanced rising motion across the western Great Lakes region (Figure 7a). Though the flow characteristics were overall similar between Cluster 1 and the LES composite (not shown), the cross-basin near-surface temperature gradient was exceptionally higher for LES systems, resulting in heightened WAA and Q-vector convergence (Figure 7d). As the upper-level feature continued to strengthen and propagate east, rising motion was observed over the eastern Great Lakes basin as evidenced by a pocket of large Q-vector convergence over the eastern lee of Lake Ontario (Figure 8a). However, the magnitude of this forcing decreased due to the increase in CAA as the clipper propagated east and surface winds acquired a northerly component (not shown). Additionally, Cluster 1 clipper's westward displacement from the upper-level feature decreased, resulting in eventual weakening of the system, and marking its transition into the mature phase. This was evidenced by MSLP tendencies as the Cluster 1 clipper's central pressure was $8 \mathrm{mb}$ higher at $75^{\circ} \mathrm{W}$ than $97.5^{\circ} \mathrm{W}$ (Figure $8 \mathrm{a}$ ). In contrast, the LES clipper's central pressure was $4 \mathrm{mb}$ lower at $75^{\circ} \mathrm{W}$ than $97.5^{\circ} \mathrm{W}$. 


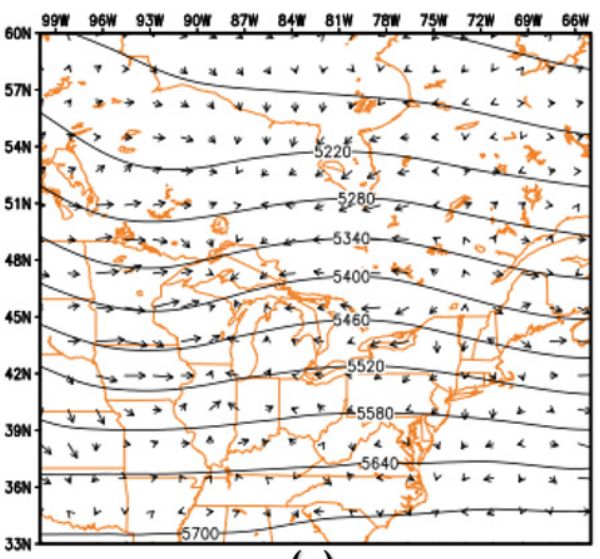

(a)

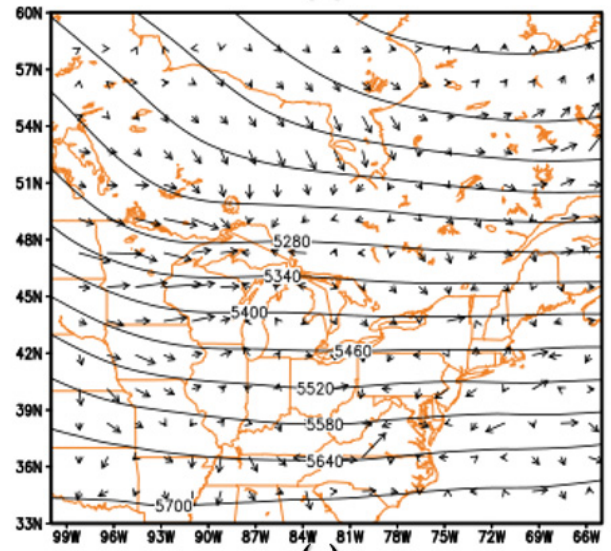

(c)

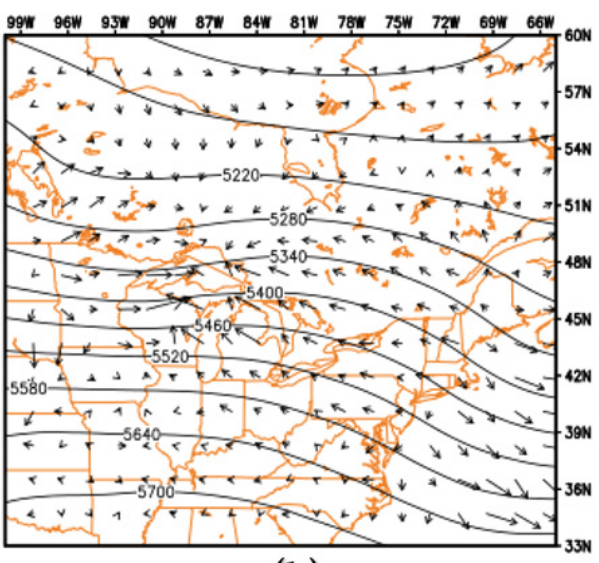

(b)

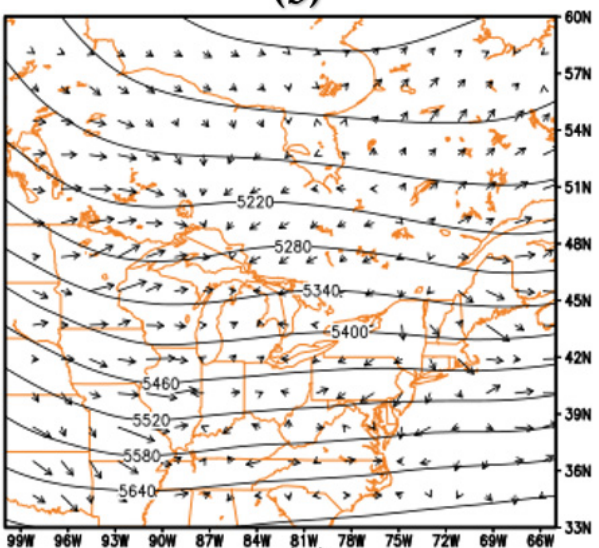

(d)

Figure 6. $500 \mathrm{mb}$ geopotential heights ( $\mathrm{m}$; contours) and Q-vectors for Cluster 1 (a), Cluster 2 (b), Cluster 3 (c), and the LES composite (d) while the clipper was located at $90^{\circ} \mathrm{W}$.

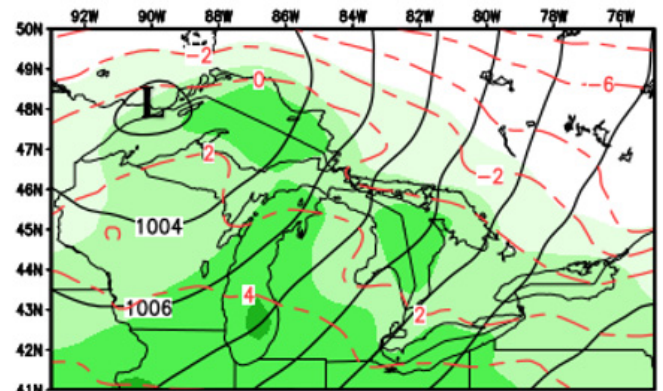

(a)

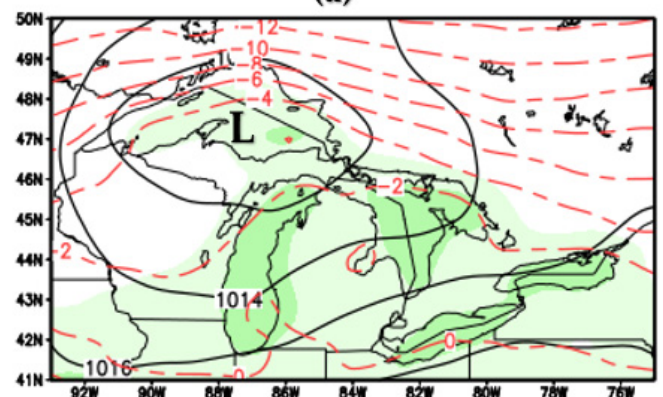

(c)

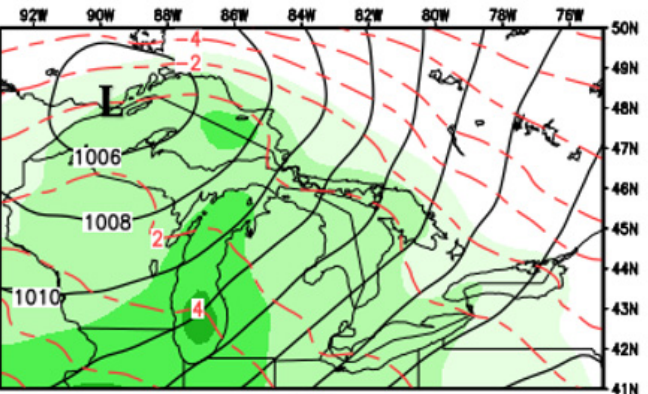

(b)

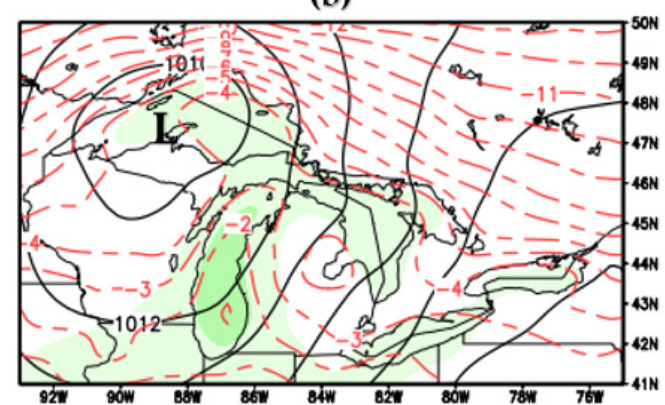

(d)

Figure 7. MSLP (solid black contours; $\mathrm{mb}$ ), $1000 \mathrm{mb}$ temperature (dashed red contours; ${ }^{\circ} \mathrm{C}$ ), and 2-m specific humidity (shaded green; $\mathrm{g} \mathrm{kg}^{-1}$ ) for Cluster 1 (a), Cluster 2 (b), Cluster 3 (c), and the LES composite (d) while the clipper was located at $90^{\circ} \mathrm{W}$. 


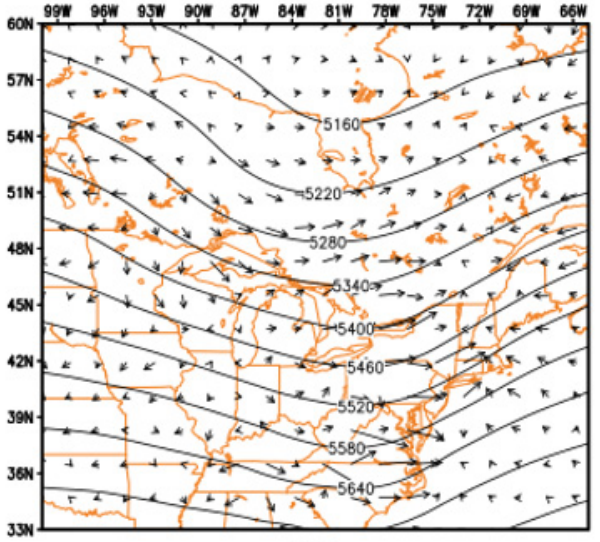

(a)

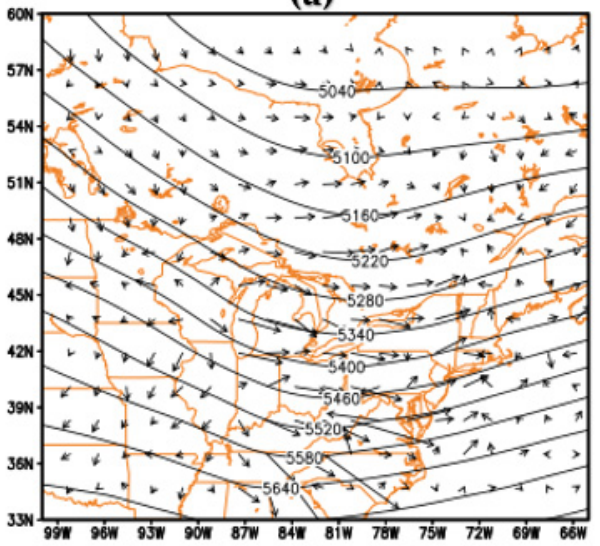

(c)

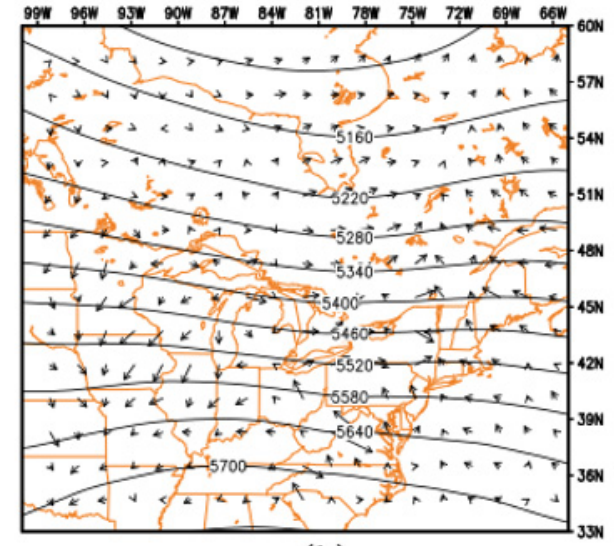

(b)

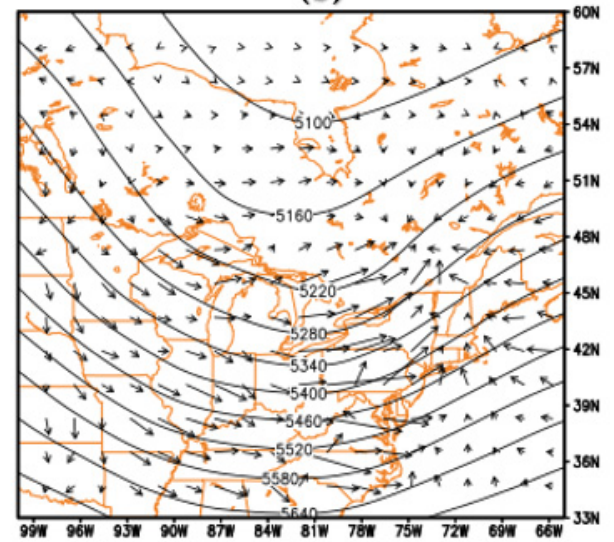

(d)

Figure 8. $500 \mathrm{mb}$ geopotential heights ( $\mathrm{m}$; contours) and Q-vectors for Cluster 1 (a), Cluster 2 (b), Cluster 3 (c), and the LES composite (d) while the clipper was located at $75^{\circ} \mathrm{W}$.

Cluster 2 composites followed a similar storm track to Cluster 1, though the overall track position was further north than LES clippers (Figure 5). Cluster 2 clippers were on average much less intense (6.3 mb higher central MSLP) than LES systems and Cluster 1 and featured shorter lifespans and faster propagation speeds (Table 5). This was partially attributed to Cluster 2 featuring the highest percentage (47.4\%) of December cases when the polar jet stream is weaker compared to January due to the lessened meridional equatorpole temperature gradient [1]. Composites showed an initial upper-level trough and associated surface cyclone that advanced zonally, strengthening through its progression. Synoptic-scale ascent was maximized over the same general region as Cluster 1 (south central Lake Superior coast) based on Q-vector fields while the clipper was located at $90^{\circ}$ W (Figure 6b). As in Cluster 1, this strengthening was attributed to WAA associated with southerly flow across the Great Lakes basin while the cyclone propagated into the study area (Figure $7 b$ ). However, the southerly flow and associated WAA inhibited convective development, making LES formation unlikely contrasted to the westerly flow observed with the LES composite (not shown).

Through Cluster 2's composite clipper progression, an upper-level vorticity maximum developed north of the Great Lakes basin as the trough-ridge pattern damped, resulting in minimal Q-vector convergence at the location when LES was most likely to form (Figure $8 \mathbf{b}$ ). This pattern contrasted LES systems that strengthened throughout their progression. As the clipper exited the Great Lakes basin (Figure 9b), an anticyclone originating from western Canada propagated southeastward, roughly following the Cluster 2 composite clipper. This resulted in the traditional high-low pressure dipole structure coupled with large-scale CAA over the north central U.S, a pattern commonly seen in previous studies $[35,36]$ during LES episodes (as well as in the LES composites). However, the absence of upper-level forcing and the relatively stable environment over the lakes (further discussed below) suppressed 
convective activity. Note that the strength of the gradient between the dipole structure was higher for LES systems as well, featuring stronger high-(1030 mb) and low-pressure $(1008 \mathrm{mb})$ systems which produced faster winds $\left(5-10 \mathrm{~m} \mathrm{~s}^{-1}\right)$. This suggests that the intensity of the dipole structure may indirectly be a differentiating factor between LES and non-LES clippers.

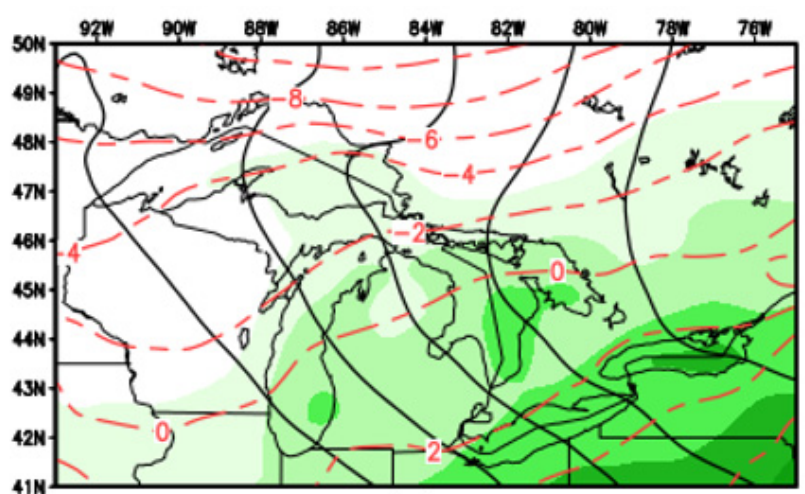

(a)

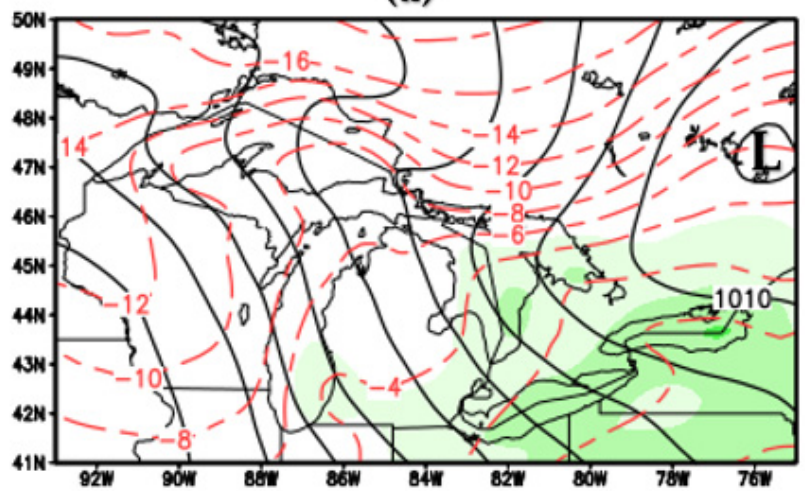

(c)

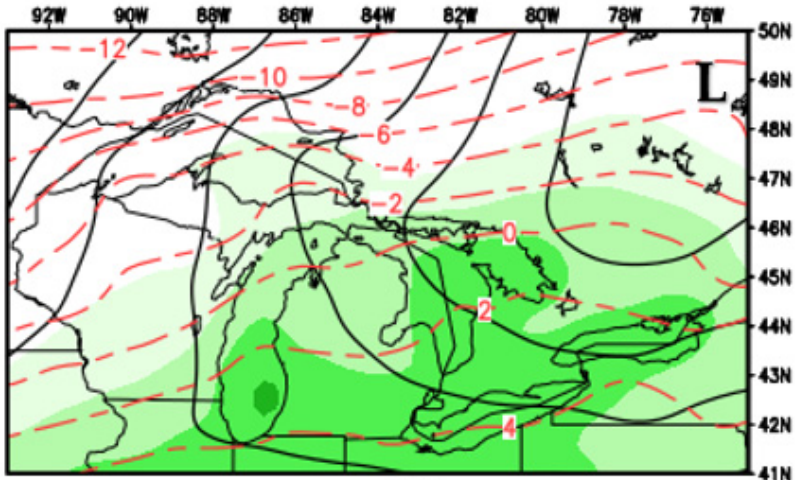

(b)

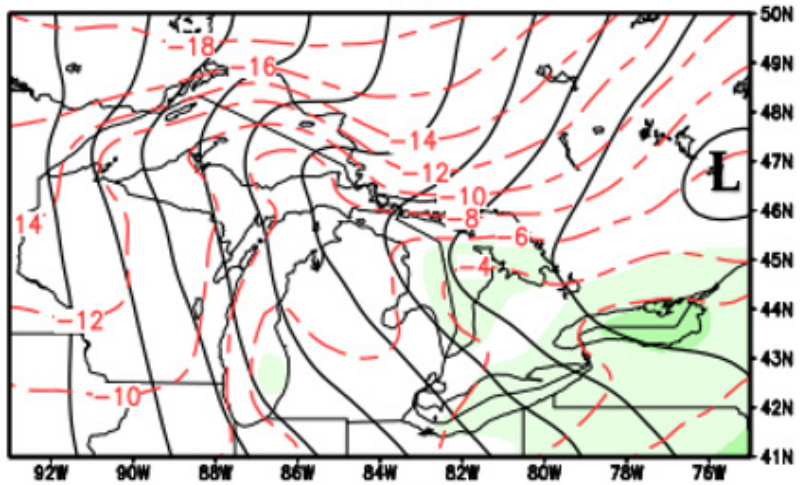

(d)

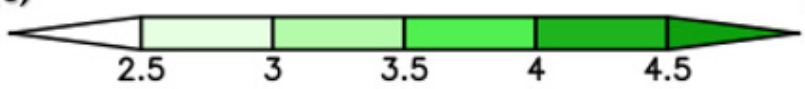

Figure 9. MSLP (solid black contours; mb), $1000 \mathrm{mb}$ temperature (dashed red contours; ${ }^{\circ} \mathrm{C}$ ), and 2 -m specific humidity (shaded green; $\mathrm{g} \mathrm{kg}^{-1}$ ) for Cluster 1 (a), Cluster 2 (b), Cluster $3(\mathbf{c})$, and the LES composite (d) while the clipper was located at $75^{\circ} \mathrm{W}$.

The synoptic structure and propagation of Cluster 3 notably differed from the first two clusters and most matched the LES composite, even though its intensity characteristics most differed. Similar to the LES composite, Cluster 3's storm track featured meridional variation absent from Clusters 1 and 2 as it originated at the northernmost location $\left(54.6^{\circ} \mathrm{N}\right)$ and followed the southernmost track (Figure 5). Cluster 3 clippers propagated faster than Clusters 1 and 2, and were weakest based on central MSLP (Table 5). The initial composite pattern featured an upper-level local vorticity maximum over northern North Dakota that was coupled with a synoptic scale $500 \mathrm{mb}$ low pressure anomaly centered over the eastern Hudson Bay, and an associated surface low-pressure system over north Minnesota (not shown). As the surface clipper system progressed southeast, the vorticity maximum strengthened initially, owing to height falls, resulting in the development of a large-scale positively tilted upper-level trough at $90^{\circ} \mathrm{W}$ (Figure 6c). Simultaneously, strong Q-vector convergence was present over Michigan's lower peninsula via strong low-level WAA (Figure 7c), shifting the upper-level trough to a neutral phase as the system propagated east. Q-vector convergence was maximized over western Lake Superior adjacent to the backend of the cyclone where WAA was strongest. Overall, synoptical vertical forcing was strongest of all clusters and closely matched the LES composite. 
As the clipper tracked eastward, the lessened displacement of the upper-level vorticity maximum from the surface cyclone reduced baroclinicity and resulted in the clipper weakening while still tracking $1^{\circ}$ latitude south of the Cluster 1 and 2 tracks. Simultaneously, an anticyclone originating from the Rocky Mountains began building in the clipper's wake from considerable CAA and anticyclonic vorticity advection (AVA) (not shown), resulting in the surface dipole structure observed in Cluster 2 and the LES composite. The orientation of the dipole suggests an eastern Great Lakes (Lakes Erie and Ontario) LES conducive environment as the southwest-northeast pressure gradient resulted in southwesterly flow across a large fetch across the two lakes. This contrasts the LES dipole that featured a purely zonal pressure gradient leading to westerly winds (not shown) across most of the Great Lakes. However, upper-level forcing was minimalized through Cluster $3^{\prime}$ s progression due to strong CAA (Figure 9c) and, as in Cluster 2, the strength of the dipole was weaker than the LES composites which generated weaker flow $\left(0-5 \mathrm{~m} \mathrm{~s}^{-1}\right)$ (not shown).

\subsection{Mesoscale and Stability Analysis}

As most of the differences in the LES and non-LES composites were in the structure and magnitude of temperature advection, a mesoscale analysis focusing on stability and temperature advection was completed to complement the synoptic analysis. For Cluster 1, WAA patterns enhanced atmospheric stability at $90^{\circ} \mathrm{W}$, which suppressed LES across the study region (Figure 7a) by modifying static stability. Relatively high inland surface temperatures combined with the low-level WAA produced the lowest low-level lapse rates $\left(3.5^{\circ} \mathrm{C} \mathrm{km}^{-1}\right)$ from Cluster 1 's environment of all composites considered (and much lower than the LES composite of $6.7^{\circ} \mathrm{C} \mathrm{km}^{-1}$ ). The flow pattern from the WAA was also unsupportive of LES, as numerous studies [18-22] have observed that north/northwesterly flow, not southerly flow, accommodates LES formation by ensuring maximum fetch across each lake (except Lake Michigan, due to its meridional orientation). Later in the clipper's track, the surface wind pattern veered significantly, resulting in westerly flow as the dominant regime when the clipper was centered $75^{\circ} \mathrm{W}$ (Figure 9a). This pattern would be most similar to a typical LES setup as more of the necessary ingredients were observed (e.g., CAA near the backend of the cyclone's life cycle and westerly flow). However, $1000 \mathrm{mb}$ temperatures over the southern half of the Great Lakes basin were above freezing throughout the clippers progression which, combined with enhanced stability and minimal upper-level forcing, may be why Cluster 1 clippers did not result in LES. These high temperatures also resulted in relatively high atmospheric moisture content with specific humidity values ranging from 3.5-4.5 $\mathrm{g} \mathrm{kg}^{-1}$ (Figures 7a and 9a). Lastly, the horizontal temperature gradient over the region was minimal compared to the LES composite, resulting in weaker CAA even though the flow regimes were similar.

Most mesoscale structures evident in Cluster 1 were also present in the Cluster 2 composites. Weak WAA owing to a minimal temperature gradient was present over the study region as the clipper entered the basin, and this advection quickly transitioned to CAA as winds acquired a westerly component in the wake of the cyclone (Figures $7 \mathrm{~b}$ and $9 \mathrm{~b}$ ). Inland $1000 \mathrm{mb}$ temperatures initially ranged from $0{ }^{\circ} \mathrm{C}$ to $-4{ }^{\circ} \mathrm{C}$ across most the basin before decreasing in the northern basin via synoptic scale CAA, supporting snowfall formation (Figure 9b). This CAA occurred while the composite clipper tracked through $75^{\circ} \mathrm{W}$, as an anticyclone propagated southeast setting up the previously mentioned dipole structure. Once again, the flow regime and CAA present at $75^{\circ} \mathrm{W}$ denotes where the environment was most conducive to LES generation. The Cluster 2 environment was less stable compared to Cluster 1, as indicated by higher low-level lapse rates $\left(4.37^{\circ} \mathrm{C} \mathrm{km}^{-1}\right.$ on average). However, this was still notably less than that of the LES composite, again suggesting high atmospheric stability was a major factor in LES suppression for Cluster 2. Additionally, similar to Cluster 1, near surface temperatures co-located with the strongest upper-level synoptic-scale support were again at or above freezing, inhibiting snow formation despite ample atmospheric moisture (Figure 9b). 
As observed with the synoptic fields, the mesoscale and surface characteristics of Cluster 3 differed the most from the other clusters. Near surface temperatures were exceptionally low over the Great Lakes basin, fluctuating between $0{ }^{\circ} \mathrm{C}$ off the southern Lake Erie and Ontario coasts to $-10^{\circ} \mathrm{C}$ over northern Lake Superior (Figure 7c), matching much more closely with what was observed with the LES composite. Southwesterly flow (not shown) occurred as the clipper entered the Great Lakes basin with considerable WAA observed east of Lake Superior. This continued as the clipper tracked east of $90^{\circ} \mathrm{W}$, resulting in inland temperatures warming $2-3{ }^{\circ} \mathrm{C}$ (Figure 7c). However, once the clipper crossed the Great Lakes basin, surface winds veered to the north, resulting in strong CAA due to the strong temperature gradient observed across the basin (Figure 9c). Upon the clipper's exit from the domain, surface temperatures fell dramatically, with some areas south of Lake Superior reaching $-14{ }^{\circ} \mathrm{C}$ (Figure 9c). In general, the Cluster 3 mesoscale environment was most conducive to LES formation. Cluster 3 featured the steepest average lapse rates $\left(5.91{ }^{\circ} \mathrm{C} \mathrm{km}^{-1}\right)$ and lowest inland surface temperatures with the entire Great Lakes basin featuring below freezing temperatures through the clippers progression.

To quantify statistical significance among the static stability differences in the LES and non-LES composites, permutation tests were run on lapse rates calculated for each storm in the LES and non-LES clipper repositories. To avoid an asymmetry of case distribution between these two clipper sets (19 LES clippers vs. 51 non-LES clippers), non-LES clippers were separated into their previously assigned clusters, leading to three sets of permutation tests run across each reference longitude. $p$-values calculated from the permutation tests showed that stability was a significant $(p \leq 0.05)$ differentiating factor between Cluster 1 clippers and LES clippers across all lakes (Table 6). This was also observed over Lakes Superior and Michigan for Cluster 2. This result is not surprising given the large inland near surface temperature contrast between these clusters and the LES composite. Similarly, the results between the Cluster 3 and LES composite lapse rates were not significantly different, which was expected based on results presented above. Interestingly, this suggests that the overlying mesoscale moisture profile was not important with regard to LES development, consistent with [21], which noted high levels of atmospheric moisture are not necessarily a mandatory requirement for LES formation and even small amounts of water vapor can result in substantial snowfall.

Table 6. Low-level (1000-850 mb) lapse rate permutation test $p$-values averaged across all reference longitudes. Starred values denote statistical significance $(p \leq 0.05)$ between non-LES clusters and the LES composites.

\begin{tabular}{lccccc}
\hline & $\begin{array}{c}\text { Lake } \\
\text { Superior }\end{array}$ & $\begin{array}{c}\text { Lake } \\
\text { Michigan }\end{array}$ & $\begin{array}{c}\text { Lake } \\
\text { Huron }\end{array}$ & $\begin{array}{c}\text { Lake } \\
\text { Erie }\end{array}$ & $\begin{array}{c}\text { Lake } \\
\text { Ontario }\end{array}$ \\
\hline Cluster 1 & $0.002 *$ & $0.005^{*}$ & $0.000^{*}$ & $0.005^{*}$ & $0.002^{*}$ \\
Cluster 2 & $0.034^{*}$ & $0.048^{*}$ & 0.076 & 0.182 & 0.072 \\
Cluster 3 & 0.357 & 0.301 & 0.368 & 0.386 & 0.676 \\
\hline
\end{tabular}

\section{Summary and Future Work}

This study's research objective was to analyze the spatial and temporal characteristics linked with non-LES associated clippers through the development of synoptic composites from a newly defined repository of clipper systems. Once clippers were identified and tracked, each was associated/disassociated with LES formation by cross referencing a previously developed LES repository. In total, 78 clippers were identified from the tracking methods, of which 57 were non-LES and 21 were LES systems. Composites were then constructed by blending a PCA with a CA that grouped non-LES clipper systems with similar atmospheric and propagation characteristics at two reference longitudes $\left(75^{\circ} \mathrm{W}\right.$ and $90^{\circ} \mathrm{W}$ ) where LES was most likely to occur. Three non-LES clusters were selected based on PCA and CA evaluation metrics. Composites of the mean LES clippers were also constructed to evaluate potential separating atmospheric characteristics crucial to LES development that differed from the non-LES composites. Additionally, daily lake surface 
temperatures and ice cover data were retained to characterize the lake surface for both LES and non-LES clippers. Permutation tests revealed that the overlying lake environment did not significantly $(p \leq 0.05)$ contrast during LES and non-LES clippers, indicating the primary differences were meteorological.

Cluster 1 featured the strongest clippers (lowest average MSLP) and propagated close to parallel with the climatological clipper track as defined by [37]. Cluster 2 exhibited a similar track to Cluster 1, though its composite average strength was weaker (5.9 mb higher central MSLP) which can be attributed to their contrast in intraseasonal distribution to the rest of the clipper repository (most Cluster 2 cases occurred in December). The Cluster 3 composite mirrored Cluster 1 in terms of intraseasonal distribution (most clippers in January), but its track had the greatest latitudinal variation and featured the weakest systems on average. This southward shift in these clippers likely contributed to their weaker magnitude (relative to Cluster 1 ) as weaker planetary vorticity was present along most of the Cluster 3 track.

Analyses revealed several differentiating characteristics among the clusters and LES composite. Low-level stability appeared to be a primary distinguishing factor for Cluster 1 as low-level lapse rates were significantly $(p \leq 0.05)$ lower than LES clippers across all the Great Lakes. Furthermore, above freezing inland surface temperatures and weak CAA also factored into why LES activity was suppressed. As [21,59] notes, ample CAA is needed to create large vertical temperature gradients which generate turbulent heat and moisture fluxes and destabilize the overlying polar air mass. Cluster 1 mesoscale patterns were observed, albeit to a lesser degree, with Cluster 2. Additionally, Lakes Superior and Michigan had significantly lower lapse rates in their non-LES environments, while the other three lakes, while not statistically significant, did possess large differences in static stability when compared to the LES cases. Upper-level forcing appeared to be another distinguishing factor between these clusters (1 and 2) and LES systems. Analysis of Q-vector divergence fields indicated large amounts of synoptic ascent across most of the Great Lakes basin early in the LES composite clipper's life cycle that was absent for Clusters 1 and 2.

These trends were not observed with Cluster 3, as the mesoscale and thermodynamic environment was similar to the LES composite. The notable differences with Cluster 3's composite were synoptic in nature and largely based on the strength of the surface dipole. LES clippers were much stronger ( $21.8 \mathrm{mb}$ lower central MSLP) than Cluster 3 systems on average, as was the anticyclone that built in the clippers wake. The subsequently strong winds in the LES composite ultimately enhanced low-level vertical heat and moisture fluxes via turbulent mixing between the lake surface and low-level atmosphere, distinguishing these patterns from the Cluster 3 composite.

As previous research has focused on the synoptic environment during LES events, the purpose of this research was to provide a baseline diagnosis of the synoptic conditions during non-LES situations associated with cyclonic systems that most frequently result in LES (i.e., clippers). These differences primarily included the presence and magnitude of synoptic forcing present, low-level stability, and the strength of the surface dipole. Future research will further investigate these meteorological traits through the development of a diagnostic objective classification model that categorizes LES and non-LES clippers based on results from this study. Reference [59] demonstrated that the climatological spatial snowfall patterns over Lake Michigan contain enough of a synoptic signal to objectively classify LES from synoptically driven snowfall. The authors plan to further this work by developing a machine learning based classifier using the results of this work. Optimizing the classifier will provide insight into which spatial scales and atmospheric fields are most important regarding LES development/suppression related to clippers. An analysis of surface temperature fields of all 19 LES and 51 non-LES cases revealed that the differentiating atmospheric fields separating these two systems goes beyond whether temperatures were above freezing. Knowledge of these physical traits will aid local forecasters and provide the foundation for future prognostic efforts. 
Author Contributions: Conceptualization, A.M. and J.W.; methodology, A.M.; software, J.W.; validation, J.W. and A.M.; formal analysis, J.W.; investigation, J.W.; resources, J.W.; data curation, J.W. and A.M.; writing—original draft preparation, J.W.; writing-review and editing, A.M.; visualization, J.W.; supervision, J.W.; and project administration, A.M. All authors have read and agreed to the published version of the manuscript.

Funding: This work was supported by NOAA award \#NA19OAR4590411.

Institutional Review Board Statement: Not applicable.

Informed Consent Statement: Not applicable.

Data Availability Statement: Data can be found in the references cited in the manuscript.

Acknowledgments: We wish to thank two anonymous reviewers for their valuable contributions to help improving this manuscript.

Conflicts of Interest: The authors declare no conflict of interest.

\section{References}

1. Lackmann, G. Midlatitude Synoptic Meteorology: Dynamics, Analysis, and Forecasting, 3rd ed.; American Meteorological Society: Boston, MA, USA, 2011; p. 98.

2. Mercer, A.E.; Shafer, C.M.; Doswell, C.A.; Leslie, L.M.; Richman, M.B. Objective Classification of Tornadic and Nontornadic Severe Weather Outbreaks. Mon. Weather Rev. 2009, 137, 4355-4368. [CrossRef]

3. Mercer, A.E.; Shafer, C.M.; Doswell, C.A.; Leslie, L.M.; Richman, M.B. Synoptic Composites of Tornadic and Nontornadic Out-breaks. Mon. Weather Rev. 2012, 140, 2590-2608. [CrossRef]

4. Trenberth, K.E.; Caron, J.M. Estimates of Meridional Atmosphere and Ocean Heat Transports. J. Clim. 2001, 14, 3433-3443. [CrossRef]

5. Geen, R.; Czaja, A.; Haigh, J.D. The effects of increasing humidity on heat transport by extratropical waves. Geophys. Res. Lett. 2016, 43, 8314-8321. [CrossRef]

6. Ferreira, R.N.; Hall, L.; Rickenbach, T.M. A Climatology of the Structure, Evolution, and Propagation of Midlatitude Cyclones in the Southeast United States. J. Clim. 2013, 26, 8406-8421. [CrossRef]

7. Kennedy, A.; Trellinger, A.; Grafenauer, T.; Gust, G. A Climatology of Atmospheric Patterns Associated with Red River Valley Blizzards. Climate 2019, 7, 1-19. [CrossRef]

8. Whittaker, L.M.; Horn, L.H. Northern Hemisphere extratropical cyclone activity for four mid-season months. J. Clim. 1984, 4, 297-310. [CrossRef]

9. Sawyer, J.S. Observational characteristics of atmospheric fluctuations with a time scale of a month. Q. J. R. Meteorol. Soc. 1970, 96, 610-625. [CrossRef]

10. Blackmon, M.L.; Wallace, J.M.; Lau, N.-C.; Mullen, S.L. An observational study of the Northern Hemisphere wintertime circulation. J. Atmos. Sci. 1977, 34, 1040-1053. [CrossRef]

11. Bosart, L.F.; Lin, S.C. A Diagnostic Analysis of the Presidents' Day Storm Of February 1979. Mon. Weather. Rev. 1984, 112, 2148-2177. [CrossRef]

12. Sanders, F. A Study of $500 \mathrm{mb}$ Vorticity Maxima Crossing the East Coast of North America and Associated Surface Cyclogenesis. Weather Forecast. 1987, 2, 70-83. [CrossRef]

13. Nakamura, H. Midwinter Suppression of Baroclinic Wave Activity in the Pacific. J. Atmos. Sci. 1992, 49, 1629-1642. [CrossRef]

14. Mercer, A.E.; Richman, M.B. Statistical Differences of Quasigeostrophic Variables, Stability, and Moisture Profiles in North American Storm Tracks. Mon. Weather Rev. 2007, 135, 2312-2338. [CrossRef]

15. Monmonier, M. Lake Effect: Tales of Large Lakes, Arctic Winds, and Recurrent Snows, 1st ed.; Syracuse University Press: Syracuse, NY, USA, 2012; p. 17.

16. Wiggin, B.L. Great Snows of the Great Lakes. Weatherwise 1950, 3, 123-126. [CrossRef]

17. Peace, R.L.; Sykes, R.B. Mesoscale study of a lake effect snow storm. Mon. Weather Rev. 1966, 94, 495-507. [CrossRef]

18. Eichenlaub, V.L. Lake Effect Snowfall to the Lee of the Great Lakes: Its Role in Michigan. Bull. Am. Meteorol. Soc. 1970, 51, 403-412. [CrossRef]

19. Niziol, T.A. Operational Forecasting of Lake Effect Snowfall in Western and Central New York. Weather Forecast. 1987, 2, 310-321. [CrossRef]

20. Niziol, T.A.; Snyder, W.R.; Waldstreicher, J.S. Winter Weather Forecasting throughout the Eastern United States. Part IV: Lake Effect Snow. Weather Forecast. 1995, 10, 61-77. [CrossRef]

21. Sousounis, P.J. Lake-Effect Storms. Encycl. Atmos. Sci. 2003, 1104-1115. [CrossRef]

22. Hjelmfelt, M.R. Numerical Study of the Influence of Enviornmental Conditions on Lake-Effect Snowstorms over Lake Michigan. Mon. Weather Rev. 1990, 3, 54-67.

23. Cordeira, J.M.; Laird, N.F. The Influence of Ice Cover on Two Lake-Effect Snow Events over Lake Erie. Mon. Weather Rev. 2008, 136, 2747-2763. [CrossRef] 
24. Vavrus, S.; Notaro, M.; Zarrin, A. The Role of Ice Cover in Heavy Lake-Effect Snowstorms over the Great Lakes Basin as Simulated by RegCM4. Mon. Weather Rev. 2013, 141, 148-165. [CrossRef]

25. Wright, D.M.; Posselt, D.J.; Steiner, A.L. Sensitivity of Lake-Effect Snowfall to Lake Ice Cover and Temperature in the Great Lakes Region. Mon. Weather Rev. 2013, 141, 670-689. [CrossRef]

26. Reeves, H.D.; Dawson, D.T. The Dependence of QPF on the Choice of Microphysical Parameterization for Lake-Effect Snowstorms. J. Appl. Meteorol. Climatol. 2013, 52, 363-377. [CrossRef]

27. Conrick, R.; Reeves, H.D.; Zhong, S. The dependence of QPF on the choice of boundary- and surface-layer parameterization for a lake-effect snowstorm. J. Appl. Meteorol. Climatol. 2015, 54, 1177-1190. [CrossRef]

28. Campbell, L.S.; Steenburgh, W.J.; Veals, P.G.; Letcher, T.W.; Minder, J.R. Lake-effect mode and precipitation enhancement over the Tug Hill Plateau during OWLeS IOP2b. Mon. Weather Rev. 2016, 144, 1729-1748. [CrossRef]

29. Bergmaier, P.T.; Geerts, B.; Campbell, L.S.; Steenburgh, W.J. The OWLeS IOP2b lake-effect snowstorm: Dynamics of the secondary circulation. Mon. Weather Rev. 2017, 145, 2437-2459. [CrossRef]

30. Kristovich, D.R.; Clark, R.D.; Frame, J.; Geerts, B.; Knupp, K.R.; Kosiba, K.A.; Laird, N.F.; Metz, N.D.; Minder, J.R.; Sikora, T.D.; et al. The Ontario winter lake-effect systems field campaign scientific and educational adventures to further our knowledge and prediction of lake-effect storms. Bull. Am. Meteorol. Soc. 2017, 98, 315-332. [CrossRef]

31. Saslo, S.; Greybush, S.J. Prediction of lake-effect snow using convection-allowing ensemble forecasts and regional data assimilation. Weather Forecast. 2017, 32, 1727-1744. [CrossRef]

32. Steenburgh, W.J.; Campbell, L.S. The OWLeS IOP2b lake-effect snowstorm: Shoreline geometry and the mesoscale forcing of precipitation. Mon. Weather Rev. 2017, 145, 2421-2436. [CrossRef]

33. Mulholland, J.P.; Frame, J.; Nesbitt, S.W.; Steiger, S.M.; Kosiba, K.A.; Wurman, J. Observations of misovortices within a long-lakeaxis-parallel lake-effect snowband during the OWLeS project. Mon. Weather Rev. 2017, 145, 3265-3291. [CrossRef]

34. Minder, J.R.; Bartolini, W.M.; Spence, C.; Hedstrom, N.R.; Blanken, P.D.; Lenters, J.D. Characterizing and constraining uncertainty associated with surface and boundary layer turbulent fluxes in simulations of lake-effect snowfall. Weather Forecast. 2020, 35, 467-488. [CrossRef]

35. Wiley, J.; Mercer, A. An Updated Synoptic Climatology of Lake Erie and Lake Ontario Heavy Lake-Effect Snow Events. Atmosphere 2020, 11, 872. [CrossRef]

36. Wiley, J.; Mercer, A. Synoptic Climatology of Lake-Effect Snow Events off the Western Great Lakes. Climate 2021, 9, 43. [CrossRef]

37. Thomas, B.C.; Martin, J.E. A synoptic climatology and composite analysis of the Alberta clipper. Weather Forecast. 2007, 22, 315-333. [CrossRef]

38. Steenburgh, W.J.; Mass, C.F. The structure and evolution of a simulated Rocky Mountain lee trough. Mon. Weather Rev. 1994, 122, 2740-2761. [CrossRef]

39. Schultz, D.M.; Doswell, C.A. Analyzing and forecasting Rocky Mountain lee cyclogenesis often associated with strong winds. Weather Forecast. 2000, 15, 152-173. [CrossRef]

40. Hutchinson, T.A. An analysis of NMC's Nested Grid Model forecasts of Alberta clippers. Weather Forecast. 1995, 10, 632-641. [CrossRef]

41. American Meteorological Society, 2021: Alberta clipper. Glossary of Meteorology. Available online: http://glossary.ametsoc.org/ wiki $\backslash \mathrm{T} 1 \backslash$ textquotedblrightAlberta_clipper $\backslash \mathrm{T} 1 \backslash$ textquotedblright (accessed on 1 April 2021).

42. Schwartz, R.M.; Schmidlin, T.W. Climatology of Blizzards in the Conterminous United States, 1959-2000. J. Clim. 2002, 15, 1765-1772. [CrossRef]

43. Heidenreich, P. Wind Gusts Reached $137 \mathrm{~km} / \mathrm{h}$ in Province on Wednesday thanks to Alberta Clipper Low-Pressure System. Global News. Available online: https://globalnews.ca/news/7575464/alberta-clipper-low-wind-record-rain-snow/ (accessed on 5 September 2021).

44. Ellis, A.W.; Leathers, D.J. A synoptic climatological approach to the analysis of lake-effect snowfall: Potential forecasting applications. Weather Forecast. 1996, 11, 216-229. [CrossRef]

45. Liu, A.Q.; Moore, G.W.K. Lake-effect snowstorms over southern Ontario, Canada, and their associated synoptic-scale environment. Mon. Weather Rev. 2004, 132, 2595-2609. [CrossRef]

46. Suriano, Z.J.; Leathers, D.J. Synoptic climatology of lake-effect snowfall conditions in the eastern Great Lakes region. Int. J. Climatol. 2017, 37, 4377-4389. [CrossRef]

47. Saha, S.; Moorthi, S.; Pan, H.-L.; Wu, X.; Wang, J.; Nadiga, S.; Tripp, P.; Kistler, R.; Woollen, J.; Behringer, D.; et al. The NCEP Climate Forecast System Reanalysis. Bull. Am. Meteorol. Soc. 2010, 91, 1015-1058. [CrossRef]

48. Grid Analysis and Display System (GrADS) The Center for Ocean-Land-Atmosphere Studies (COLA). George Mason University. Available online: http:/ / cola.gmu.edu/grads/grads.php (accessed on 1 April 2021).

49. ESRI. ArcGIS Pro: Release 2.1.0 Redlands; Environmental Systems Research Institute: Redlands, CA, USA, 2021.

50. Zolina, O.; Gulev, S.K. Improving the accuracy of mapping cyclone numbers and frequencies. Mon. Weather Rev. 2002, 130, 748-759. [CrossRef]

51. Marciano, C.G.; Lackmann, G.M.; Robinson, W.A. Changes in U.S. East Coast cyclone dynamics with climate change. J. Clim. 2015, 28, 468-484. [CrossRef]

52. Mesinger, F.; DiMego, G.; Kalnay, E.; Mitchell, K.; Shafran, P.C.; Ebisuzaki, W.; Jovi'c, D.; Woollen, J.; Rogers, E.; Berbery, E.H.; et al. North American Regional Reanalysis. Bull. Am. Meteorol. Soc. 2006, 87, 343-360. [CrossRef] 
53. Rousseeuw, P.J. Silhouettes: A graphical aid to the interpretation and validation for cluster analysis. J. Comput. Appl. Math. 1987, 20, 53-65. [CrossRef]

54. Hoskins, B.J.; Draghici, I.; Davies, H.C. A new look at the w-equation. Q. J. R. Meteorol. Soc. 1978, 104, 31-38. [CrossRef]

55. NOAA Great Lakes Environmental Research Laboratory. Available online: https://coastwatch.glerl.noaa.gov/statistic/ (accessed on 9 July 2021).

56. Wilks, D.S. Statistical Methods in the Atmospheric Sciences; Academic Press: Cambridge, MA, USA, $2019 ;$ p. 182.

57. Bjerknes, J. On the structure of moving cyclones. Geofys. Publ. 1919, 1, 1-8. [CrossRef]

58. Xiao, C.; Lofgren, B.M.; Wang, J. WRF-based assessment of the Great Lakes' impact on cold season synoptic cyclones. Atmos. Res. 2018, 214, 189-203. [CrossRef]

59. Clark, C.A.; Goebbert, K.H.; Ganesh-Babu, B.; Young, A.M.; Heinlein, K.N.; Casas, E.G.; VanDe Guchte, A.P.; Krull, A.J.; Sefcovic, Z.P.; Connelly, R.J.; et al. Classification of Lake Michigan snow days for estimation of the lake-effect contribution to the downward trend in November snowfall. Int. J. Climatol. 2020, 40, 5656-5670. [CrossRef] 